\title{
O DESIGN GRÁFICO INCLUSIVO COMO FERRAMENTA DE EMPODERAMENTO DE JOVENS NEGRAS
}

Cristina de Souza Corat

Universidade Estadual Paulista "Júlio de Mesquita Filho" (UNESP)

Fernanda Henriques, Dra

Universidade Estadual Paulista "Júlio de Mesquita Filho" (UNESP)

ferdi@faac.unesp.com

Resumo: Como herança da sociedade patriarcal, a mulher brasileira sofre diariamente opressão. Para as mulheres negras, a discriminação não ocorre apenas pela questão de gênero, mas também racial, sendo colocadas no grupo mais inferior da sociedade, afetando o modo como enxergam a si mesmas. Dessa forma, este estudo tem como objetivo organizar bases teóricas relacionadas ao movimento feminista negro e desenvolver um produto de design gráfico inclusivo para conscientizar e auxiliar o empoderamento ${ }^{1}$ de jovens negras. A metodologia da pesquisa está estruturada em dois eixos, um teórico e outro prático. O primeiro eixo é constituído de pesquisa bibliográfica e imagética sobre os principais temas da investigação (movimento feminista negro; estética e cultura afrobrasileira e design social e inclusivo com foco em integração social), pesquisa de projetos sociais e feministas que utilizem o design como ferramenta de comunicação e, a partir de estatísticas nacionais, identificação dos principais fatores de opressão às mulheres negras para investigação de ações eficientes para o fortalecimento de identidade. 0 segundo eixo consiste na elaboração de uma oficina com dez jovens entre nove e dezoito anos (que se identificam como negras) com intuito de discussão acerca do feminismo negro, investigação sobre design de interação e animação como forma de comunicação, análise dos resultados e desenvolvimento de material gráfico específico para a pesquisa. Como resultado esperado, visa-se o desenvolvimento de uma animação de caráter comunicativo e informativo com finalidade de auxiliar a conscientização e a capacidade de jovens negras de realizarem mudanças necessárias para evoluirem e se fortalecerem como indivíduos.

Palavras-chave: Feminismo Negro, Design Gráfico Inclusivo, Design de Interação, Animação

\footnotetext{
1 Para este trabalho utilizaremos o termo "empoderamento" que, segundo Paulo Freire, é o fato de a pessoa, o grupo, ou instituição realizar, por si mesma, as mudanças e ações que a levam a evoluir e se fortalecer. Também o adotamos pois esta expressão é de uso corrente e promove maior proximidade com o assunto abordado.
} 


\begin{abstract}
As a legacy of the patriarchal society, the Brazilian woman suffers daily oppression. For black women, discrimination occurs not only the in issue of gender, but also race, being placed on the lower section of society, affecting the way they see themselves. Thus, this study aims to organize theoretical basis related to the black feminist movement and develop a product of graphic design to raise awareness and support the empowerment of young black women. The research methodology is structured in two axes, a theoretical and a practical. The first axis is constituted of bibliographic and imagery research on the main subjects of inquiry (black feminist movement, aesthetics and African-Brazilian culture and social and inclusive design with a focus on social integration), research of social and feminist projects that use design as a communication tool and, from national statistics, identification key factors of oppression of black women to investigate what actions are most effective for strengthening identity. The second axis consists in developing a workshop with ten young women between nine and eighteen years old (who identify themselves as black) with the purpose of discussion about the black feminism, research on interaction design and animation as a means of communication, analysis of results and development of specific graphic material for the research. As expected results, the aim is to develop an animation with an interactive, communicative and informative purpose of assisting the awareness and the ability of young black women to accomplish changes needed to evolve and strengthen themselves as individuals.
\end{abstract}

Keywords: Black Feminism, Inclusive Graphic Design, Interactive Design, Animation

\title{
1. INTRODUÇÃO
}

Cultura é o conceito de diferentes modos de organização da vida social, atribuindo-se tanto à humanidade como um todo quanto às nações, às sociedades e aos grupos sociais. Refere-se aos modos de vida de qualquer agrupamento de pessoas, cujos costumes, comportamentos e formas de pensar são compartilhados e transmitidos entre aqueles que a compõem e passados de uma geração a outra. $A$ cultura de uma sociedade expressa suas transformações políticas, econômicas, históricas e sociais, diferindo umas das outras de acordo com a organização de valores e crenças de tal sociedade. É importante salientar que o período histórico e a posição social do indivíduo são fundamentais para a determinação de sua cultura frente à sociedade em que está inserido, transmitindo suas particularidades para os demais membros. (BORIS; CESÍDIO, 2007, p.454)

Com suas transformações, a cultura de uma sociedade pode modificar-se com o tempo, porém, em alguns aspectos, tais mudanças são limitadas, de forma que características históricas ultrapassadas permanecem na atualidade. Dentre as características que iremos abordar nessa pesquisa, inclui-se a herança do patriarcado na sociedade e a desigualdade gênero-raciais. 
Ainda que na atualidade a questão dos malefícios ou supostos benefícios do machismo estejam gerando brigas acirradas, não podemos nos furtar de definir que o machismo é uma ideologia que diferencia homens e mulheres em relação a privilégios e poderes.

A sociedade patriarcal, proveniente do período colonial, tem como perfil o homem como autoridade maior da família, sendo o núcleo de poder tanto familiar quanto econômico. Dentro dessa sociedade, a mulher está sempre submetida aos interesses do patriarca, tendo a obrigação de obedecer o homem ao qual pertence e seguir o que ele dita ser certo e errado, não tendo voz de opinião. A mulher é criada para ser propriedade do homem.

Esse sistema social foi e é presente em muitos países e comunidades e, no caso do Brasil, teve seu início na colonização, adquirindo essa característica da tradição portuguesa. Assim, o principal beneficiado do patriarcado é o homem rico, branco e adulto da elite urbana. Porém, o aspecto de poder masculino também é presente nas classes mais pobres e entre os escravos. Além disso, a religião sustentava a manutenção dos valores vigentes, atribuindo à quebra desses princípios castigos divinos.

Junto com a colonização, o intenso tráfico de escravos africanos trouxe para o Brasil milhões de negros para serem utilizados como mão-de-obra na produção de cana-de-açúcar. Com essa vinda intensa, tornou-se significativa a presença negra na constituição da população brasileira. Os castigos eram frequentes, sendo o chicote a punição mais utilizada no Brasil colônia. Aos negros era vetado o direito de exercer sua religião de ascendência africana e manter a sua cultura. Festas e rituais africanos eram terminantemente proibidos em detrimento da imposição de professar a religião católica e comunicar-se utilizando a língua portuguesa. Os escravos, ocultamente, realizavam seus rituais e suas festas, havendo nesse período o desenvolvimento da capoeira. Eles também desenvolveram o candomblé, a umbanda, e outras religiões, nas quais ritos africanos eram mesclados a elementos do catolicismo, dando origem ao sincretismo religioso brasileiro.

A mulher escrava negra desempenhava diferentes papéis nas fazendas, desde tarefas domésticas até trabalhos com a terra, o que seria o plantio e a lida com a cana de açúcar. Vítimas do patriarcado, além da submissão ao patrão, inúmeros são os casos de estupros por parte do homem branco, com a justificativa de preferência sexual dos senhores de engenho pelas negras, com uma imagem erotizada que até hoje alimenta o estereótipo negativo de mulata associado à mulher negra. A mulher branca era a mulher para casar e a negra a mulher para a libido e relações sexuais.

Com o processo de urbanização e ida de famílias para o meio urbano, a mulher branca pôde conquistar maior socialização com pessoas de fora da família, além de acesso à educação. Porém, isso ocorreu com muita discriminação e dificuldade, pois a sociedade se opunha à profissionalização da mulher. Foi somente no final do século XIX que a mulher passou a obter avanços na sociedade, pois haviam mulheres que sabiam ler e escrever. Com o começo de uma nova era de industrialização, avanço da tecnologia e sofisticação de máquinas, houve uma demanda de mais trabalhadores para aumentar a produção. Isto abriu a oportunidade para a mulher ter acesso ao mercado de trabalho e aos meios de produção, tendo a possibilidade de se desenvolver como profissional. Houve assim a abertura para a independência pessoal da mulher no Brasil. 
Também no final do século XIX ocorreu a Abolição da Escravidão. A inserção do negro como não-escravo na sociedade passou sem nenhuma política de reparação e de reversão ao racismo, sem nenhum método de remuneração e auxílio ao mercado de trabalho. Pelo contrário, a política de embranquecimento da população trouxe imigrantes europeus e asiáticos para ocuparem o espaço de trabalho, que havia pertencido até então à população negra. A marginalização do negro era evidente e propaga-se até os dias atuais, com claros indicadores de discriminação em aspectos como trabalho, renda, escolaridade, reconhecimento e valorização social.

A mulher negra, no contexto pós-Abolição, encontrava-se sem lugar, sem trabalho, sem nenhum tipo de assistência por parte do estado para minimamente reparar os 300 anos de escravidão. Não cabiam muitas opções às mulheres negras, ou ficavam nas fazendas em que já trabalhavam, ou iriam tentar oportunidades de trabalho em outros lugares, que não eram muitas devido ao seu passado. Algumas conseguiam trabalhos autônomos, porém, para a imensa maioria, somente se fez disponível a prestação de serviços domésticos de baixa remuneração (TOKITA, 2013, p.122). Ainda hoje, as negras são a grande maioria de mulheres empregadas como domésticas, acumulando-se o fato de serem a última categoria profissional a ter garantidos os direitos trabalhistas essenciais.

Ao mesmo tempo que as mulheres, num todo, tentavam conseguir seu espaço na sociedade, o fator racial colocou e coloca a mulher negra numa posição inferior à mulher branca.

\footnotetext{
Ali aquele homem diz que as mulheres precisam de ajuda para subir às carruagens, para passar a sarjetas e para ter sempre, em qualquer lado os melhores lugares. Nunca ninguém me ajuda a subir às carruagens, ou me dá o melhor lugar e não sou eu uma mulher?

Olhem para mim, olhem para os meus braços. Eu lavrei, eu plantei, eu armazenei e nenhum homem me passava à frente. E não sou eu uma mulher? Eu poderia trabalhar tanto como um homem, e comer tanto (sempre que arranjasse comida) como um homem. E igualmente suportar o chicote! E não sou eu uma mulher? (OLIVEIRA, 2010, p.27)
}

Esse relato de uma ex-escrava mostra as disparidades entre mulheres que se perpetuou ao longo da história, não só entre negras e brancas, mas também com outras ditas minorias, como as indígenas. $O$ feminismo centrado apenas nas diferenças de gênero e sexuais não seria suficiente para explicar as contradições vividas pelas mulheres negras.

Algumas estatísticas mostram bem as diferenças gênero-raciais presentes no Brasil. Segundo Venturi (2007), mulheres afirmam que há machismo no Brasil (89\%), e muito (73\%). As desigualdades baseadas em discriminações de gênero aparecem nas assimétricas distribuições de tarefas domésticas, e ficam alarmantes quando $49 \%$ das mulheres entrevistadas afirmam terem sofrido violência sexista por parte de um homem. De acordo com Werneck (2010), mesmo com a enorme densidade demográfica de mulheres negras, calculada em 2010, em aproximadamente 50 milhões, elas recebem, pelo mesmo trabalho, 2,7 vezes menos que homens brancos, 1,8 menos que mulheres brancas, e 1,3 menos que homens negros. Martins (2006) explica que a mortalidade materna, configurada como questão de saúde pública, é um dos prejuízos da desigualdade racial e tem maior risco para mulheres negras devido a condições econômicas, características genéticas e também pela incidência das 
opressões de gênero e de raça, o que faz com que mulheres negras, em diferentes regiões do Brasil, tenham risco maior de óbito no parto e puerpério, por motivos muitas vezes evitáveis, numa razão de 1,5 a 7,4 vezes maior que mulheres brancas.

Ainda se torna necessário estabelecer um espaço legítimo para a construção de uma identidade negra positiva, assim como, de reivindicação de direitos e melhores condições de vida. Atualmente, o feminismo negro cresce bastante e conquista cada vez mais espaços, causando discussões e debates nos espaços sociais. 0 movimento tem buscado divulgar a questão negra, propondo alternativas e pensando em ações que valorizem seu papel frente a sociedade e as permita ocupar espaços e direitos que Ihes foram historicamente negados.

É a partir dessa necessidade de ações de divulgação e debate que essa pesquisa estuda a utilização do design gráfico de forma inclusiva e social, com o uso de peças gráficas animadas, a fim de comunicar, conscientizar e ajudar o empoderamento de jovens negras.

O design social visa o estudo do maior número de possibilidades de uso, quer de um produto, quer de ambientes e serviços pelo maior número de pessoas. Dessa forma, é pensado o impacto mais amplo desses serviços nos indivíduos, incluindo impactos sociais, ambientais e econômicos. Segundo Paschoarelli e Da Silva (2009): “A função do designer nesse aspecto é justamente vencer o desafio de propor soluções inclusivas, visando extinguir a segregação causada por barreiras físicas e sociais".

O feminismo negro e o empoderamento são fundamentais para refletir sobre situações de opressão e dominação invisíveis, sendo capaz de fazer dos espaços e das instâncias de opressão, lugares de resistência e de exercício de poder. É importante para esta pesquisa a aplicação da estética afro-brasileira como forma de resistência, focando no princípio de que trabalhar e afirmar à estética afro-brasileira é dialogar com o corpo

feminino como forma de poder e reconhecimento, mostrando orgulho de pertencimento.

\section{DESENVOLVIMENTO}

Este estudo tem como objetivo pesquisar e organizar bases teóricas relacionadas ao movimento feminista negro para o desenvolvimento de um vídeo de animação de caráter comunicativo e informativo, em conjunto com metodologias de design social. A principal finalidade é aproximar o design social dos projetos de design gráfico para promover transformações sociais.

Dessa forma, auxiliar a conscientização e a capacidade de jovens negras de realizarem mudanças necessárias para evoluirem e se fortalecerem como indivíduos, frente à sociedade machista e racista.

Como metodologia, o estudo está estruturado em:

1- Pesquisa bibliográfica e imagética dos principais focos da pesquisa: a) Movimento feminista negro; b) Estética e cultura afro-brasileira; c) Design social e inclusivo com foco em integração social.

2- Pesquisa de projetos sociais e feministas que, preferencialmente, façam uso do design social e de imagens gráficas como forma de ação e divulgação.

3- Com base na pesquisa bibliográfica, imagética e de projetos, identificar os principais fatores de opressão à mulheres negras e as ações mais eficientes de fortalecimento de identidade. 
4- Utilizar as ações de resistência como base para a elaboração de uma oficina com jovens entre 9 e 18 anos, em que será feito um questionário e uma discussão à cerca do feminismo negro com foco em: a) Estética afro-brasileira; b) Formas de opressão; c) Valorização do corpo e da cultura afro; d) Auto imagem.

5- Elaboração de uma animação que comunique o empoderamento de jovens negras, com base nos resultados adquiridos anteriormente.

\subsection{Desenvolvimento da Metodologia}

Através de estudos sobre o feminismo negro, foi possível determinar uma base para a pesquisa num todo, devido às pautas muito bem definidas do movimento. $A$ essência do feminismo negro é a interseccionalidade, a preocupação em se discutir gênero, raça e classe, devido a invizibilização da categoria "raça" no nascente movimento de mulheres (o chamado "feminismo branco") e a falta de consideração das relações de gênero no movimento negro geral (CARNEIRO, 2003).

Nessa pesquisa são abordados três focos do movimento. Primeiro, a questão da estética negra e afro-brasileira, seguido pela representatividade da mulher negra e , por fim, a mulher negra no mercado de trabalho.

A indústria da beleza é cruel com todas as mulheres, principalmente com as mulheres negras. Há uma valorização excessiva de padrões estéticos e traços físicos europeus, o que gera uma desvalorização da figura da mulher negra, que no Brasil corresponde a $23 \%$ da população (AMNB - Articulação de Mulheres Negras Brasileiras, 2015). Esse fato leva, além da propagação do racismo, à autoestima extremamente baixa dessa população e à negação de suas características corporais, como cabelo, nariz e pele.

Essa invisibilidade do ser negra traz uma imagem negativa dessas mulheres, sendo mostradas na mídia ou como uma figura sexual, ou como uma pessoa destinada ao trabalho subalterno. A quantidade de representantes negras é ínfima nos diversos meios: televisão, cinema, livros (inclusive didáticos), propagandas, embalagens, brinquedos, entre outros. Em todos esses meios a mulher negra dificilmente tem destaque, sendo na maioria das vezes tratada como coadjuvante, numa clara naturalização do racismo e do machismo.

Esses fatos se refletem na posição da mulher negra no mercado de trabalho, que a deixa com a maior taxa de desemprego do país. Apesar dessas mulheres entrarem mais cedo e saírem mais tarde do mercado de trabalho, elas têm o rendimento médio mais baixo da sociedade, seguidas pelos homens negros, mulheres brancas e no topo, com maior rendimento, homens brancos.

Para o combate do racismo machista, este projeto procura a valorização do corpo e da cultura afro e o empoderamento pessoal através da informação. Como referência, o estudo enaltece projetos como Think Olga, Aurélia: dicionário ilustrado de mulheres, e Outras Meninas. Todos esses projetos desenvolvem na web um trabalho de empoderamento e incentivo à maior representatividade da mulher negra, inclusive através de artes gráficas.

O Think Olga traz ilustrações e infográficos em conjunto com matérias sobre feminismo. Seu maior destaque é o projeto Chega de Fiu Fiu, um mapa do Brasil na plataforma Google, em que as mulheres podem marcar onde já foram assediadas e adicionar detalhes da história, para que outras mulheres fiquem atentas ao passarem pelo mesmo local. 
O Aurélia e o Outras Meninas fazem ilustrações de mulheres, contanto suas histórias e como o empoderamento foi importante para elas. O primeiro é específico sobre mulheres famosas e influents, o segundo é sobre mulheres comuns e desconhecidas, o que promove uma empatia maior da população.

\subsection{Figuras}

Para o desenvolvimento da animação, estão sendo criados personagens e cenário, com base nos estudos citados na metodologia. Há a preocupação da criação de personagens de aparências e corpos diferentes, para promover a diversidade e evitar a generalização normalmente adotada à associação de mulheres negras. A Figura 1 exalta a valorização excessiva de padrões estéticos europeus e desvalorização da figura da mulher negra. Já a Figura 2 mostra a consequente invizibilização da população negra na mídia e em elementos de representatividade.

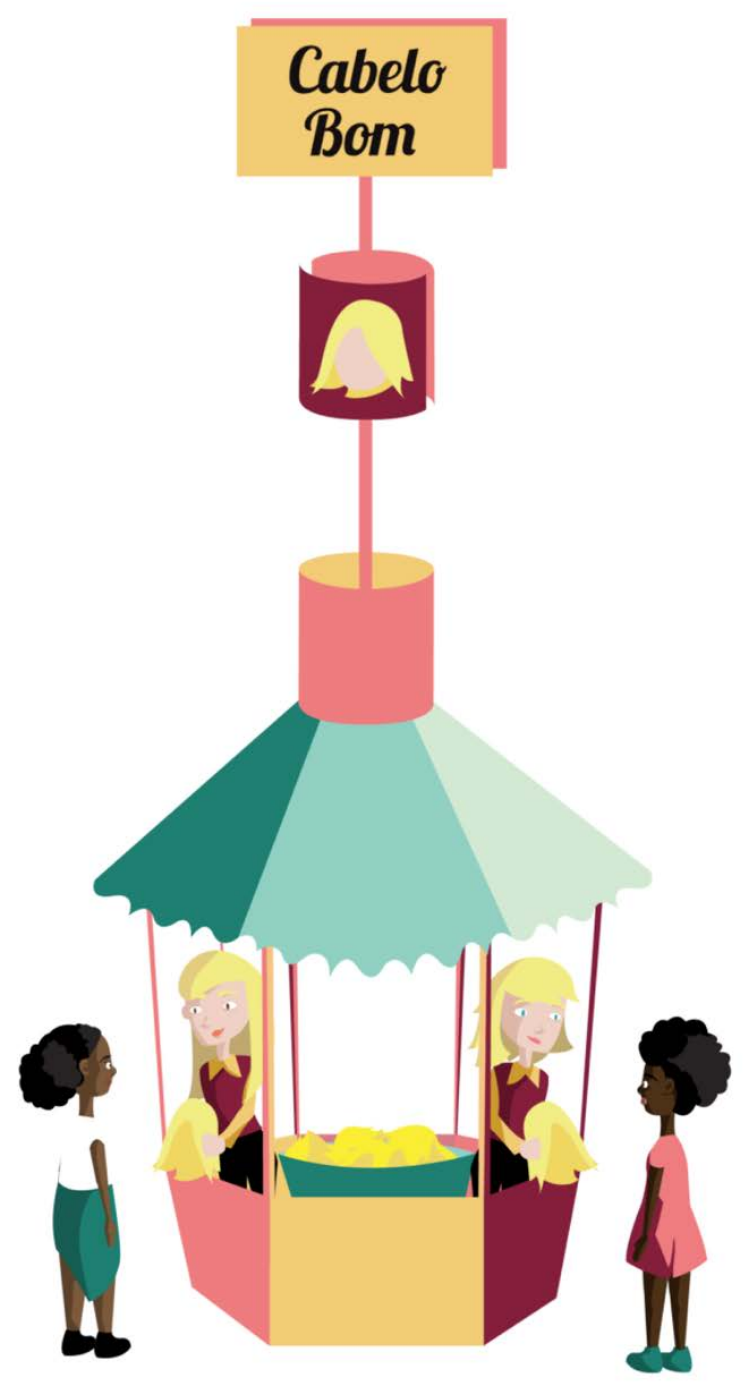

Figura 1 - Barraca Cabelo Bom

Fonte: Elaborado pelo autor, com base na pesquisa realizada 


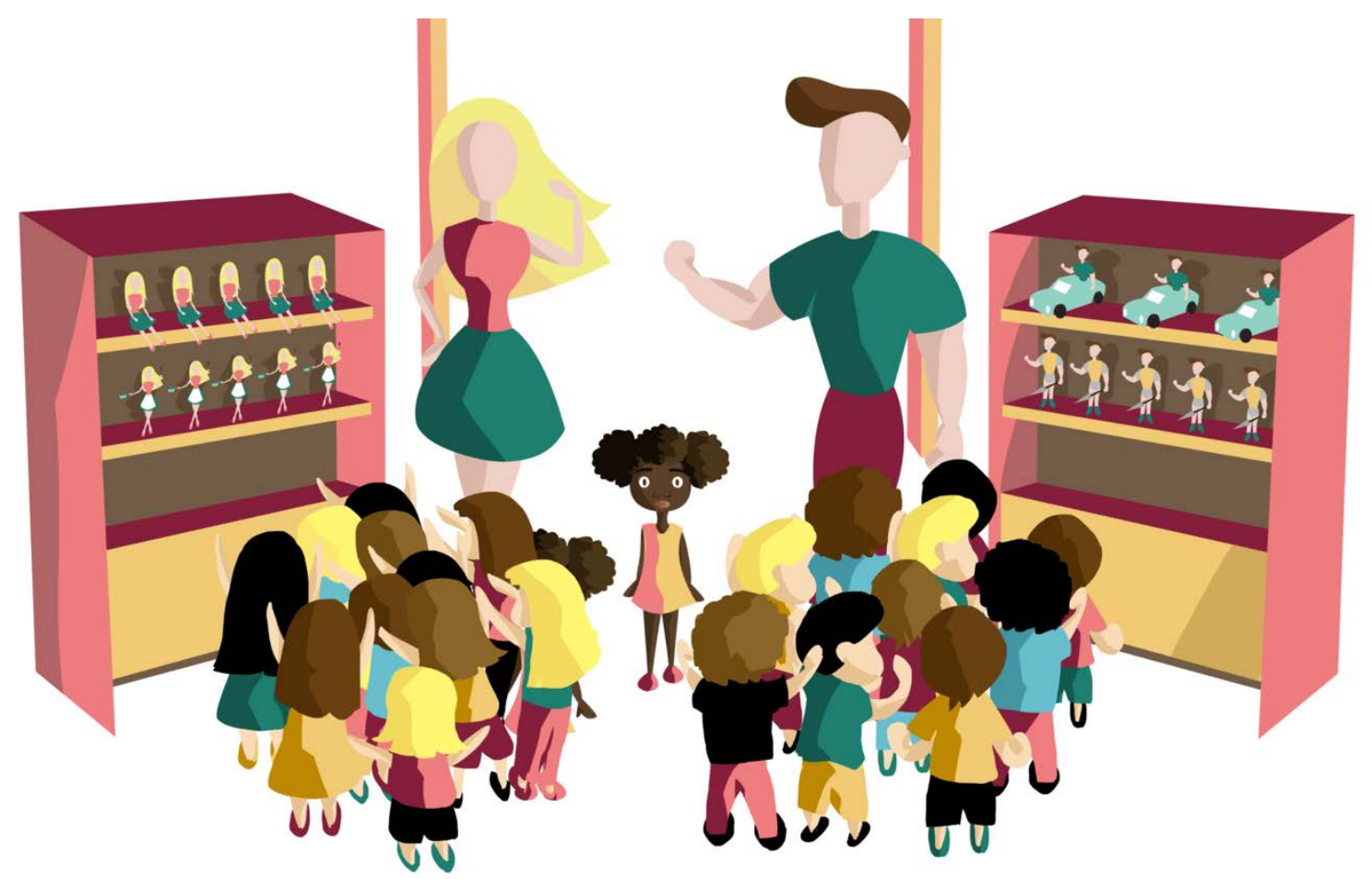

Figura 2 - Barracas de brinquedo

Fonte: Elaborado pelo autor, com base na pesquisa realizada

\section{CONCLUSÃO}

A sociedade brasileira propaga um racismo histórico, acompanhado pelo machismo, que barra os direitos de milhares de mulheres negras no país. Faz-se necessário estabelecer um espaço legítimo para a construção de uma identidade negra positiva, assim como, de reivindicação de direitos e boas condições de vida. $O$ design tem um papel fundamental nesse contexto, propondo soluções que gerem impactos sociais positivos e, através de suas ferramentas, comunicar efetivamente sua mensagem. A informação é uma aliada do design e a forma como este a difunde pode ser poderosa a transformadora.

\section{REFERÊNCIAS}

BORGES, Roberto Carlos da Silva. Representação de mulheres negras: cinema, ethos e identidades. Cuiabá: Revista Educação Pública, 2012.

BORIS, Georges Daniel Janja Bloc; CESÍDIO, Mirella de Holanda. Mulher, corpo e subjetividade: uma análise desde o patriarcado à contemporaneidade. Fortaleza: Revista Mal-Estar e Subjetividade, 2007.

BROWN, Tim. Design for Social Impact. The Rockefeller Foundation, 2008.

CARNEIRO, S. Mulheres em movimento. Estudos Avançados, 17(49), 2003, p. 117-132.

CASTRO, Jorge Abrahão de; ARAÚJO, Herton Ellery. Situação social brasileira: monitoramento das condições de vida 2. Brasília: Ipea, 2012.

CUNHAS, Manu. Outras Meninas. Brasil, 2015. Disponível na Internet por http em: <http:// http://outrasmeninas.tumblr.com/>. Acesso em abr.2016 
DE FARIA, Juliana. Think Olga. Brasil, 2013. Disponível na Internet por http em: <http://thinkolga.com/>. Acesso em abr.2016

MARGOLIN, Victor; MARGOLIN, Sylvia. A “Social Model” of Design: Issues of Practice and Research. Massachusetts: Design Issues: Volume 18, Number 4, 2002.

MARTINS, Alaerte Leandro. Mortalidade materna de mulheres negras no Brasil. Rio de Janeiro: Cad. Saúde Pública, v. 22, n. 11, Nov. 2006.

MENEGHEL, Stela Nazareth; FARINA, Olga; RAMÃO, Silvia Regina. História de resistência de mulheres negras. Florianópolis: Estudos Feministas, 2005.

PASCHOARELLI e DA SILVA (org.). Design e ergonomia: aspectos tecnológicos. São Paulo: Cultura Acadêmica, 2009.

PRESTES, Clélia Rosane dos Santos. Feridas até o coração, erguem-se negras guerreiras. Resiliência em mulheres negras: transmissão psíquica e pertencimentos. São paulo: Instituto de Psicologia da Universidade de São Paulo, 2013.

RODRIGUES, Cristiano. Atualidade do conceito de interseccionalidade para a pesquisa e prática feminista no Brasil. Florianópolis: Seminário Internacional Fazendo Gênero 10, 2013.

SANTOS, Cecília Macdowell; IZUMINO, Wânia Pasinato. Violência contra as Mulheres e Violência de Gênero: Notas sobre Estudos Feministas no Brasil. E.I.A.L, Vol 16, 2005.

SHERMAN, William R.; CRAIG, Alan B. Understanding Virtual Reality: Interface, Application, and Design. São Francisco, CA: Morgan Kaufmann Publishers, 2003.

SILVEIRA, Cecilia. Aurélia: dicionário ilustrado de mulheres. Brasil, 2015. Disponível na Internet por http em: <http://dicionarioaurelia.tumblr.com/>. Acesso em abr.2016

TOKITA, Márcia Figueiredo. Mulheres Negras. GT 7. Feminismos, sexualidades e marxismos na América Latina, 2013.

VENTURI, Gustavo. Misoginia, homofobia, racismo e "gerontofobia": contribuições de análises da opinião pública para a prevenção. Curitiba: Juruá, 2012.

WERNECK, Jurema. Políticas públicas para negras e negros. Criola, Fundação Heinrich Boll, 2010. 